\title{
FDG PET/CT findings in secondary hyperparathyroidism not mimicking multiple bone metastases
}

\author{
Elise Le Stanc • Clement Wattel • Amine Hameg • \\ Didier Vilain - Catherine Tainturier • \\ Christine Theodore
}

Received: 10 October 2008 / Accepted: 1 November 2008 / Published online: 18 December 2008

(C) Springer-Verlag 2008

We present the case of a 47-year-old man with a previous history of testicular seminoma in 1995 and lymph node metastases in 1997 . He had suffered from chronic renal failure since 1998, with severe secondary hyperparathyroidism. Because of an increased $\beta \mathrm{hCG}$ (human chorionic gonadotropin beta-subunit) at $0.4 \mathrm{U} / 1$, an ${ }^{18} \mathrm{~F}$-FDG PET/CT scan was requested before kidney transplantation. Maximum intensity projection PET images $(A)$ showed multiple areas of increased uptake involving the vertebral plates (which formed a 'ladder' pattern), both clavicles, the shoulders and hip joints, the femora and pelvis cortical bone, and a small focus in the right scapula, corresponding to an osteolysis $(B, C)$. Because this bone uptake distribution, especially in the spine, is very close to the 'rugger jersey spine' observed on radiographs in patients with hyperparathyroidism [1], this diagnosis was suggested, and the right scapula focus considered as a brown tumour.

Eight months after kidney transplantation, the hyperparathyroidism subsided, PET/CT scan displayed no abnormal bony uptake $(D, F)$, the scapula lesion had ossified $(E)$ and the $\beta$ hCG had returned to normal.

Bony FDG uptake in hyperparathyroidism may mimic bone metastases [2]. But, in our patient, the unusual pattern, similar to the radiographic findings in hyperparathyroidism, strongly suggested hyperparathyroidism rather than metastases, which was confirmed by the normalization

E. Le Stanc $\cdot$ C. Wattel $\cdot$ A. Hameg $\cdot$ D. Vilain $\cdot$ C. Tainturier

Department of Nuclear Medicine, Foch Hospital,

40 rue Worth, BP 36, 92151 Suresnes Cedex, France

C. Theodore

Department of Oncology, Foch Hospital,

40 rue Worth, BP 36, 92151 Suresnes Cedex, France

D. Vilain $(\square)$

Service de Médecine Nucléaire, Hôpital Foch, 40 rue Worth, BP 36, 92151 Suresnes Cedex, France

e-mail: d.vilain@hopital-foch.org

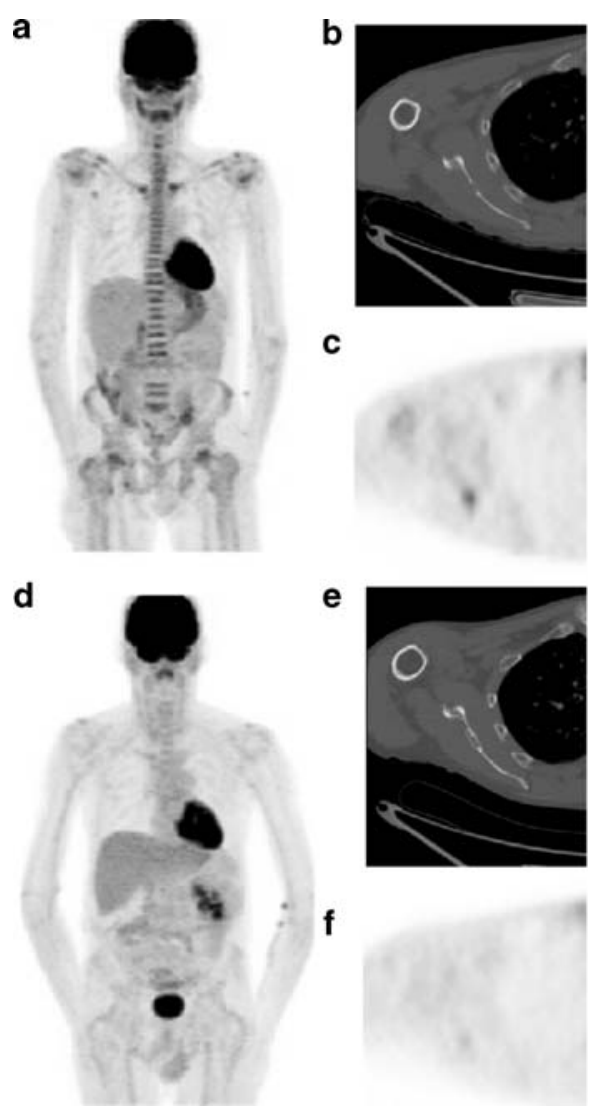

of $\beta$ hCG and the decrease in bone FDG uptake after renal transplantation.

\section{References}

1. Helms CA. Fundamentals of skeletal radiology. Philadelphia: Elsevier-Saunders; 2005. p. 143-50.

2. Demir H, Halac M, Gorur GD, Sonmezoglu K, Uslu I. FDG PET/ CT findings in primary hyperparathyroidism mimicking multiple bone metastases. Eur J Nucl Med Mol Imaging 2008;35:686. 